\title{
Influence of Steel Slag-Superfine Blast Furnace Slag Composite Mineral Admixture on the Properties of Mortar and Concrete
}

\author{
Zhenguo Liu $\mathbb{D i D}^{1}$ and Zongxian Huang $\mathbb{D}^{2}$ \\ ${ }^{1}$ Beijing Urban Construction Group Co., Ltd., Beijing, China \\ ${ }^{2}$ Department of Civil Engineering, Tsinghua University, Beijing, China \\ Correspondence should be addressed to Zongxian Huang; huang-zx18@mails.tsinghua.edu.cn
}

Received 30 September 2021; Revised 4 November 2021; Accepted 5 November 2021; Published 23 November 2021

Academic Editor: Prinya Chindaprasirt

Copyright ( $) 2021$ Zhenguo Liu and Zongxian Huang. This is an open access article distributed under the Creative Commons Attribution License, which permits unrestricted use, distribution, and reproduction in any medium, provided the original work is properly cited.

\begin{abstract}
A composite mineral admixture was prepared by steel slag and superfine blast furnace slag. The influence of superfine blast furnace slag content of the composite mixture on the mortar and concrete was investigated. The results show that the composite mineral admixture may decrease the strength of concrete at the early age but improve the strength development over time. Increasing the content of superfine blast furnace slag can reduce the degradation of the early strength. The reduction of the autogenous shrinkage and adiabatic temperature rise is significant when the composite mineral admixture is added. The reduction is more obvious when the water-to-solid ratio (w/s) is low. The results show that with steel slag and superfine blast furnace slag playing as complementary parts in the composite mineral admixture, it can be used as an effective substitute of cement.
\end{abstract}

\section{Introduction}

To combat halt global warming, the emission of $\mathrm{CO}_{2}$ and other greenhouse gases needs to be zero or even negative [1]. Cement production is a process with high energy consumption and high carbon emission. $\mathrm{CO}_{2}$ emission from the cement industry accounts for $7 \%$ of the world's total emissions [1]. The production of $1 \mathrm{t}$ cement clinker emits about $1 \mathrm{t} \mathrm{CO}_{2}, 0.74 \mathrm{~kg} \mathrm{SO}$ and $1.15 \mathrm{~kg} \mathrm{NO}_{x}$ (including the emissions from the use of fossil fuel during cement production) [2-4]. Using renewable energy is an important technology to reduce $\mathrm{CO}_{2}$ emission. But this method cannot completely reduce the $\mathrm{CO}_{2}$ emission of the cement industry. The $\mathrm{CO}_{2}$ emission of energy consumption accounts for $40-60 \%$ of the total emission in cement production $[5,6]$. The chemical reaction occurring in the production of cement is a process that inherently emits $\mathrm{CO}_{2}$. Therefore, substituting cement by pozzolanic materials or other materials with hydration activity to reduce clinker usage is important. In recent decades, different kinds of supplementary cementitious materials (SCMs) were developed [7]. Some SCMs have not been extensively used yet, and new
SCMs are still being developed [7]. Compared to the plain cement concrete, the concrete mixed with SCMs might have several pros and cons. The mechanical properties, chemical resistance, and interfacial transition zone (ITZ) are usually improved [8]. However, some SCMs degrade the properties of concrete, so these SCMs are not extensively used on a large scale. For instance, the addition of fly ash and steel slag decreases the early strength of concrete. Therefore, eliminating the negative effects and fully utilizing the properties of these SCMs is a strategy for reducing clinker usage. One of the important technical routes is to use composite SCMs, which can take advantage of performance characteristics of different admixtures and fully utilize them. Wang et al.[9] found that the composite admixture of steel slag and ground blast furnace slag can eliminate the negative effect of steel slag on the pore structure of concrete. Han et al. [10] found that the pore structure of cement is refined when using fly ash-steel slag composite admixtures. The temperature rise and later age compressive strength were also improved [10]. From those literatures, it is obvious that composite admixture has several advantages compared to single admixture. Fineness is reported as an important factor on the 
reactivity of admixture $[11,12]$. However few studies were conducted on the composite admixture with ultrafine SCMs. Therefore, the study on the composite admixture with ultrafine SCMs is worth conducting.

Steel slag (SS) is a byproduct in the process of steel production [13]. The world's annual output of steel slag exceeds 1.6 billion tons every year [14]. Steel slag mainly consists of $\mathrm{CaO}$, $\mathrm{SiO}_{2}, \mathrm{MgO}$, and $\mathrm{Fe}_{2} \mathrm{O}_{3}$ [15-18]. The main mineral compositions of steel slag are $\mathrm{C}_{2} \mathrm{~S}, \mathrm{C}_{3} \mathrm{~S}, \mathrm{C}_{2} \mathrm{~F}, \mathrm{C}_{4} \mathrm{AF}$, and $\mathrm{RO}$ phase and f-CaO [15-17]. At present, steel slag has been studied for producing bricks [18], ceramics [19], pavement materials [20], and aggregates of concrete [21]. Due to the existence of Cacontaining minerals and amorphous phase in steel slag, it shows a certain level of hydration activity [16, 17]. Consequently, steel slag is considered as a potential mineral admixture. Researches have shown that the addition of steel slag in concrete can reduce the reaction heat of cement hydration, the adiabatic temperature rises, and the early autogenous shrinkage of concrete [22]. However, adding steel slag can also reduce the compressive strength of concrete [23]. Steel slag has less cementitious minerals compared to cement, which makes the degree of hydration lower than that of cement particles [24]. The larger particles in the steel slag have few cementitious properties due to the high content of RO phase. The interface between the large steel slag particles and the C-S-H is relatively weak [25]. Therefore, the addition of steel slag in concrete can decrease both the mechanical and durability properties of concrete.

Blast furnace slag (BFS) is a mineral admixture with pozzolanic activity, which has been used as common supplementary cementitious materials in concrete [26]. However, the "effective utilization" of BFS is low. Wu et al. [26] found that the pozzolanic reaction mainly occurred on the surface of slag. The reaction rate of large particles in BFS was higher than the small particles [27]. This means that increasing the fineness and specific surface area of slag can improve the utilization efficiency of BFS. Zhu et al. [28] found that the fineness significantly affected the reaction activity of BFS. Thus, superfine blast furnace slag (SBFS) can be a better alternative than blast furnace slag (BFS) as mineral admixture. According to Luo et al. [29], using SBFS as a supplementary material for cement accelerated the cement hydration. Besides, the filler effect of ultrafine powder can increase or at least not decrease the strength of the concrete [30]. The SBFS acted as microfiller [31] in the interface transition zone (ITZ). The filling effect of finer particles increases the packing density of the cement matrix and improves the pore structure of the concrete. Therefore, using SS and SBFS as complementary parts in the mineral admixture to replace parts of cement in concrete can be an effective way to reduce the amount of cement production.

In this paper, a composite mineral admixture was produced by adding the SBFS to SS. The workability and the compressive strength of the mortar were tested under different $\mathrm{w} / \mathrm{s}$. The compressive strength of the concrete mixed with composite mineral admixture was tested. The workability, compressive strength, and adiabatic temperature rise and autogenous shrinkage of the self-compacting concrete were tested in this paper.

\section{Materials and Methods}

2.1. Raw Materials. The cement used in this study was ordinary Portland cement (OPC) with the strength grade of 42.5 complying with the Chinese National Standard GB 1752007. The specific surface area of OPC is $350 \mathrm{~m}^{2} / \mathrm{kg}$. The specific surface areas of SS and SBFS used in this study are $455 \mathrm{~m}^{2} / \mathrm{kg}$ and $639 \mathrm{~m}^{2} / \mathrm{kg}$, respectively. The chemical compositions of OPC, SS, and SBFS are presented in Table 1. The polycarboxylate (PCE) superplasticizer was used to adjust the concrete fluidity.

2.2. Test Method. The mortar and concrete were prepared to test the compressive strength. The mortars were mixed by a planet mixer. After adding the water, the pastes were mixed at a low speed for 30 seconds, followed by the addition of sands, and then a 4-minute mixing was conducted. The mortars were cast in $40 \mathrm{~mm} \times 40 \mathrm{~mm} \times 160 \mathrm{~mm}$ molds and cured under the standard curing conditions $\left(20 \pm 2^{\circ} \mathrm{C}, 95 \%\right.$ $\mathrm{RH})$.

The concrete was mixed using a pan mixer. The powder materials were dry-mixed for 5 minutes in order to make the powder more homogeneous. Water-PCE suspension was gradually added into the mixer after the dry-mixing. The whole mixing process had lasted for 15 minutes. The concrete was cast in $100 \mathrm{~mm} \times 100 \mathrm{~mm} \times 100 \mathrm{~mm}$ molds and cured under the standard curing conditions. The mix proportions of different concrete are described in the following sections.

Adiabatic temperature rises of the concrete were measured by a specific temperature measuring instrument. The measurement accuracy of the instrument is $0.1^{\circ} \mathrm{C}$. The concrete was put into the instrument after the mixing.

A horizontal noncontact autogenous shrinkage measurement was carried out to measure the autogenous shrinkage of the concrete. The noncontact autogenous shrinkage measurement of concrete can measure the shrinkage of the cement of concrete at the early age.

\section{Results and Discussion}

\subsection{Mortar Performance}

3.1.1. Fluidity of the Mortar. Fluidity is one of the important properties of concrete. The fluidity of concrete is affected by complex factors such as particle size distribution, surface humidity of the aggregate, and overall environment when mixing. Therefore, in this paper, the fluidity ratio experiment of mortar is conducted to characterize the impact of the composite mineral admixture on the fluidity. The test was carried out according to the Chinese national standard GB/T 2419-2016. The w/s ratio of the mortar is fixed at 0.47 and the cementitious material-to-sand ratio is $1: 3$. The total content of the composite admixture was set as $30 \%$. The fluidity of mortar is correlated to the packing density of mortar solid particles [32]. Generally, the higher the packing density is, the more water is released on the particle surface to form a so-called "water film" [32]. The thickness of the water film plays an important role in lubricating between particles, 
TABle 1: Chemical compositions of the material (w.t.\%).

\begin{tabular}{lccccccccc}
\hline Sample & $\mathrm{CaO}$ & $\mathrm{SiO}_{2}$ & $\mathrm{Al}_{2} \mathrm{O}_{3}$ & $\mathrm{Fe}_{2} \mathrm{O}_{3}$ & $\mathrm{MgO}$ & $\mathrm{K}_{2} \mathrm{O}$ & $\mathrm{NaO}^{2}$ & $\mathrm{SO}_{3}$ & $\mathrm{Loss}$ \\
\hline OPC & 57.21 & 22.36 & 7.73 & 3.66 & 3.10 & 0.23 & 0.73 & 3.54 & 2.31 \\
SS & 43.37 & 19.10 & 7.46 & 18.01 & 5.17 & 0.63 & 0.41 & - & 1.36 \\
SBFS & 40.26 & 34.39 & 13.78 & 0.19 & 7.43 & 0.44 & 0.3 & 1.92 & 3.5 \\
\hline
\end{tabular}

affecting the rheology and adhesiveness of mortar [32]. Different particle sizes of admixtures have great influences on the packing density of the mortar. Theoretically, if the particle size is smaller than the cement particle size, the packing density of cementitious material is higher, and the thickness of "water film" increases. But the actual situation is not necessarily the case. Because the small particles have larger specific surface area and greater adhesion to water, the thickness of "water film" does not necessarily become greater. SBFS used in this study has a smaller particle size than SS powder. Therefore, in order to explore the influence of different components in the composite admixture on the fluidity, five groups of experiments with different SBFS content were set in this section (total content of composite admixture is $30 \%$ ). The component of the composite admixture and the fluidity ratio are shown in Table 2.

Table 2 demonstrates that when the total content of composite admixture is fixed, the fluidity ratio of mortar gradually decreases as the content of SBFS increases from 0 to $25 \%$ of the total amount of the composite mineral admixture. This indicates that the fluidity of mortar decreases with the addition of the SBFS. The reason of this is that the SBFS $\left(639 \mathrm{~m}^{2} / \mathrm{kg}\right)$ used in this study has a larger specific surface area and stronger adhesion to water than SS $\left(455 \mathrm{~m}^{2} / \mathrm{kg}\right)$; therefore, the "water film" on the particle surface is thinner, resulting in the decrease of fluidity. Although more water is released due to the small particle size of SBFS, it cannot offset the loss of water film thickness due to the high specific surface.

3.1.2. Compressive Strength of the Mortar. In order to investigate the influence of composite admixtures on the compressive strength, two w/s (0.5 and 0.4) and two total contents of composite admixtures (20\% and $30 \%)$ were set. Additionally, in order to study the effect of SBFS content on the mortar strength, four groups with different SBFS content were set. The content of these four groups is the same as S-1, S-2, S-3, and S-4 in Table 2. The mix proportions of the mortar are shown in Table 3 (w/s is 0.5) and Table 4 (waterto-cement ratio is 0.4 ).

Figure 1 shows that the $3 \mathrm{~d}$ compressive strength of mortar mixed with composite admixture is lower than that of pure cement mortar. This is mainly due to the fact that the addition of the mineral admixture reduces the cementitious materials, which can undergo hydration reaction in the early stage. Therefore, the strength decreases because of less hydration products providing strength in the early stage. However, with the increase of curing age, the strength development of mortar mixed with composite mineral admixture grows higher than that of pure cement mortar. At
TABle 2: The component of the composite admixture and the fluidity ratio of the mortar for fluidity ratio experiment.

\begin{tabular}{lccc}
\hline Group & SS (\%) & SBFS (\%) & Fluidity ratio \\
\hline S0 & 100 & 0 & 107 \\
S1 & 90 & 10 & 102 \\
S2 & 85 & 15 & 100 \\
S3 & 80 & 20 & 98 \\
S4 & 75 & 25 & 96 \\
\hline
\end{tabular}

TABle 3: Mix proportion (w/s is 0.5 ) of mortar containing composite mineral admixture for compressive strength test $(\mathrm{kg})$.

\begin{tabular}{lccccc}
\hline Group & Cement & SS & SBFS & Sand & Water \\
\hline C1 & 450 & 0 & 0 & & \\
S1-20\% & & 81 & 9 & & \\
S2-20\% & & 76.5 & 13.5 & & \\
S3-20\% & 360 & 72 & 18 & & \\
S4-20\% & & 67.5 & 22.5 & 1350 & 225 \\
S1-30\% & & 121.5 & 13.5 & & \\
S2-30\% & \multirow{2}{*}{315} & 114.7 & 20.3 & & \\
S3-30\% & & 108 & 27 & & \\
S4-30\% & & 101.2 & 33.8 & & \\
\hline
\end{tabular}

TABle 4: Mix proportion (w/s is 0.5 ) of mortar containing composite mineral admixture for compressive strength test $(\mathrm{kg})$.

\begin{tabular}{lccccc}
\hline Group & Cement & SS & SBFS & Sand & Water \\
\hline C1 & 450 & 0 & 0 & & \\
S1-20\% & & 81 & 9 & & \\
S2-20\% & \multirow{2}{*}{360} & 76.5 & 13.5 & & \\
S3-20\% & & 72 & 18 & & \\
S4-20\% & & 67.5 & 22.5 & 1350 & 180 \\
S1-30\% & & 121.5 & 13.5 & & \\
S2-30\% & \multirow{2}{*}{315} & 114.7 & 20.3 & & \\
S3-30\% & & 108 & 27 & & \\
S4-30\% & & 101.2 & 33.8 & & \\
\hline
\end{tabular}

$90 \mathrm{~d}$, the strength of mortar mixed with composite admixture becomes even higher than pure cement mortar.

The $3 \mathrm{~d}$ and $28 \mathrm{~d}$ strength of pure cement mortar reach $41.5 \%$ and $81.4 \%$ of the $90 \mathrm{~d}$ strength, respectively. While the strengths of $3 \mathrm{~d}$ and $28 \mathrm{~d}$ of the highest composite admixture mortar group only account for $38.6 \%$ and $78.8 \%$ of that of $90 \mathrm{~d}$. This indicates that although the early strength of composite admixture mortar is lower, it shows a better performance in the later strength development. This can be explained by the fact that the activity of SS and SBFS is lower than that of cement in early hydration. The main active components of SS are similar to that of cement, while the 


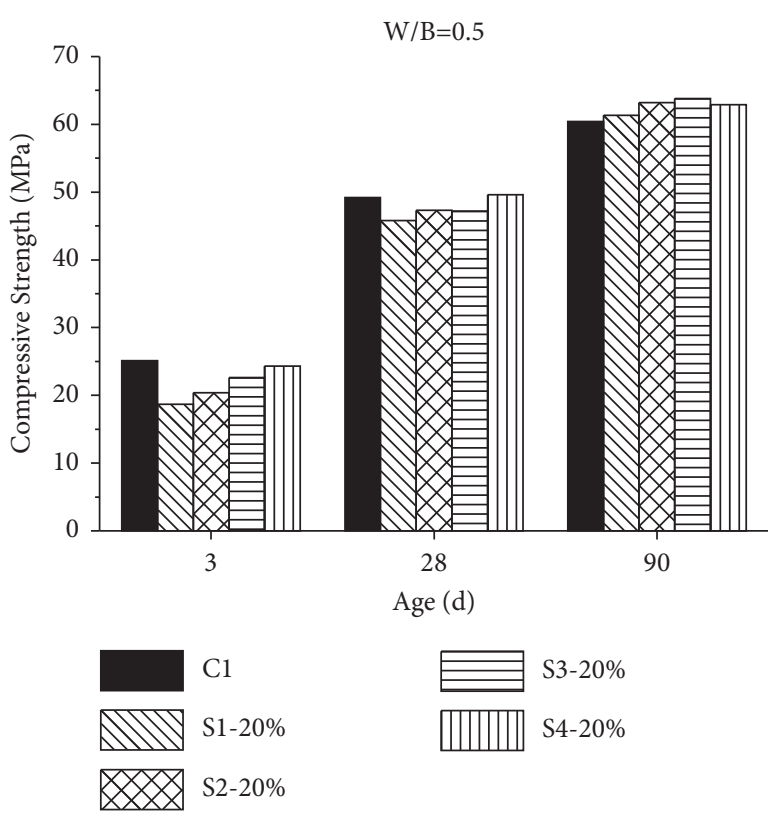

(a)
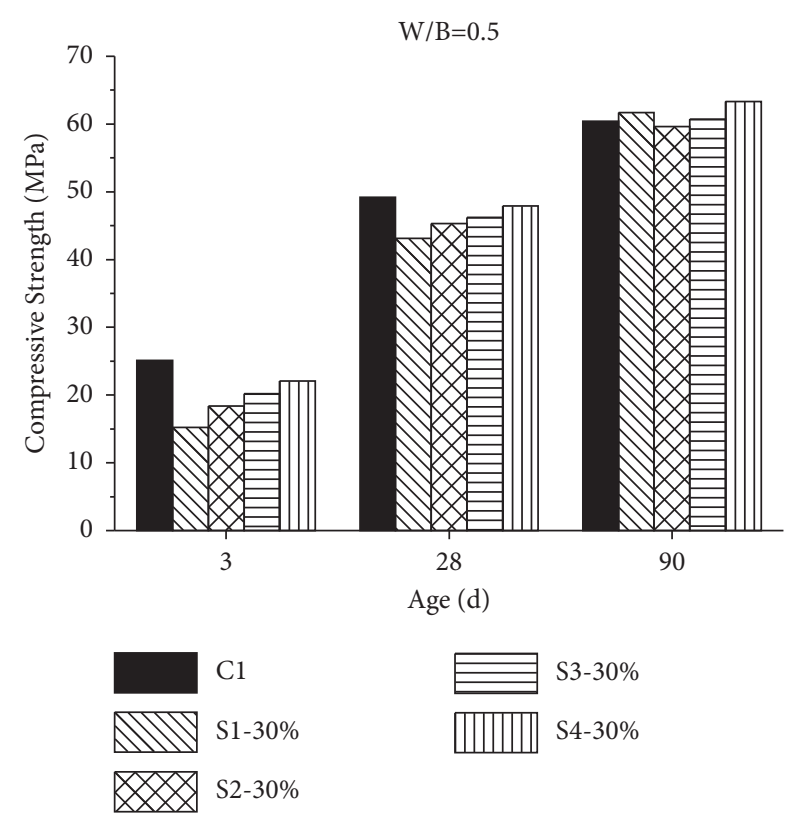

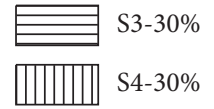

(b)

Figure 1: Compressive strength of pure cement mortar and composite admixture mortar (w/s ratio is 0.5 ). The total content of composite admixture is (a) $20 \%$ and (b) $30 \%$.

hydration rate is lower than cement $[15,16]$. The main component of SBFS is amorphous aluminosilicate. These amorphous phases can react with the $\mathrm{Ca}(\mathrm{OH})_{2}$, which is the byproducts of cement hydration. This reaction produces gel materials that create bonding on particle interface, enhancing mortar strength. The reaction is called "pozzolanic reaction." These two minerals react in the later stage, which improves the later strength of mortar.

Comparing Figures 1(a) and 1(b), it can be found that when the composition of the composite admixture is fixed, with the increase of the composite admixture content, the early strength is lower, but the later strength is higher. This also indicates that although adding more composite admixture reduces the early strength, it has little impact on the $90 \mathrm{~d}$ strength. This is because at a high w/s ratio ( 0.5 in this case), cement particles have enough water to undergo hydration reaction and produce plenty of products to fill the pores of the paste. Consequently, the weakest position is the interface between the paste and SS as well as SBFS. With the development of curing age, SS and SBFS gradually react and produce cementitious products to enhance their interfaces, so that the microstructure of the weakest position can be refined. However, because the total pore structure is mainly determined by $\mathrm{w} / \mathrm{s}$, there is little difference in strength at $90 \mathrm{~d}$.

Figure 1 also shows that when the composite admixture content is fixed, the mortar strength of $3 \mathrm{~d}$ gradually grows with the increase of the content of SBFS. This phenomenon is not obvious at the later age. The result shows that SBFS can improve the early strength of mortar compared to SS. The reason of this is that SBFS with a small particle size can fill in the small pores of cementitious material, therefore improving the compactness of mortar $[31,32]$. Besides, the filling of SBFS also releases water in pores so that more water can be consumed for cement hydration. Thus, the degree of early hydration of cement is higher. SBFS can also promote the nucleation of C-S-H and the early hydration of cement $[33,34]$. In addition, the activity of SBFS is higher than SS. SS reacts with $\mathrm{Ca}(\mathrm{OH})_{2}$ at the early age because of its high specific surface area. The reaction improves the pore structure of the matrix, which can also enhance the strength of mortar. This indicates that the addition of SBFS can significantly mitigate the negative effect of SS on the strength of mortar at the early age. Therefore, mixing SBFS and SS in the composite mineral admixture is more efficient and effective than using only one of them. With the utilization of this kind of composite mineral admixture, the cement usage is expected to be reduced.

Figure 2 shows the mortar strength with w/s of 0.4 . The phenomenon of the compressive strength is similar to that with $\mathrm{w} / \mathrm{s}$ of 0.5 . However, compared with the group w/s of 0.5 , the difference between pure cement mortar and composite admixture mortar at $3 \mathrm{~d}$ is significantly narrowed. This shows that when the w/s ratio is low, the negative effect of composite admixture on early strength is less. This can be explained from two perspectives. (1) When the w/s ratio is low, the space between particles is small. Although the addition of SS can reduce the generation of hydration products, the hydration products of cement are enough to fill the pores between SS and cement when the reaction degree is high. Therefore, the adverse effect of SS on pore structure is insignificant. (2) The addition of SS increases the actual water-to-cement ratio and raises the degree of hydration. This phenomenon is not obvious when the water-to-cement ratio is high. However, when the w/s is low, the water-release effect of SS is more obvious, therefore promoting the cement hydration. 


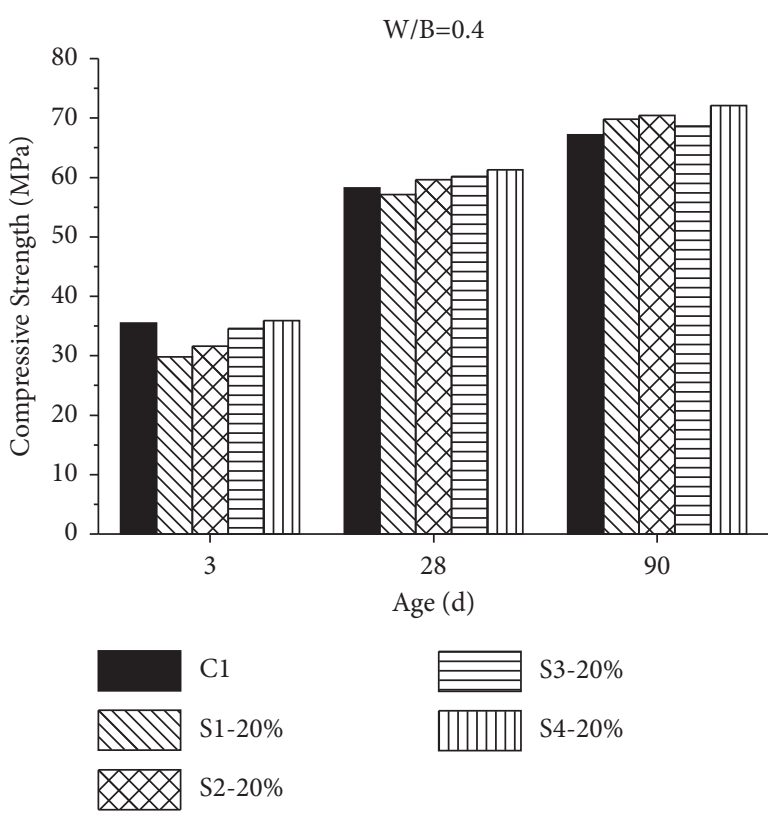

(a)
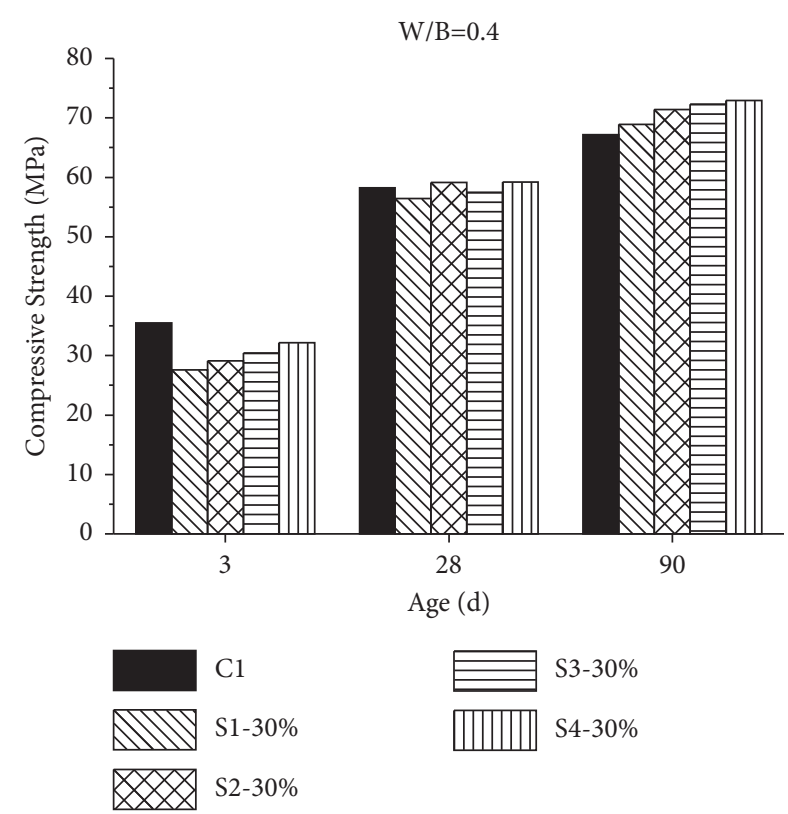

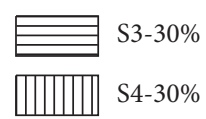

(b)

Figure 2: Compressive strength of pure cement mortar and composite admixture mortar (water-to-solid ratio is 0.4). The total content of composite admixture is (a) $20 \%$ and (b) $30 \%$.

Comparing Figures 2(a) and 2(b), it can also be found that when the $\mathrm{w} / \mathrm{s}$ is 0.5 , with the development of age, the tendency of the strength increasing as the content of SBFS increases becomes less obvious. When the w/s is 0.4 , with the addition of SBFS, the enhancement of strength is still observable at the $90 \mathrm{~d}$. This shows when the w/s is low, SBFS can not only improve the early mortar strength but also improve the later mortar strength. When the $\mathrm{w} / \mathrm{s}$ is 0.5 , the pore structure development is weak. The later strength is determined by the w/s. The result shows that the composite mineral admixture is more efficient at a low $\mathrm{w} / \mathrm{s}$ ratio.

\subsection{Compressive Strength of the Ordinary Concrete. Two} different grades of concrete (C30 and C40) were designed. In order to use cement more efficiently, two types of concrete with different cement content were also designed for each grade. The mix proportion of the concrete is shown in Table 5.

Figure 3 shows the compressive strength of concrete mixed with composite mineral admixture. It can be seen from Figure 3 that with the addition of the SBFS, $28 \mathrm{~d}$ and $90 \mathrm{~d}$ strength of concrete are increased. This indicates that SBFS can increase the compressive strength of concrete, which is consistent with the compressive strength of mortar. The reason for that is that the addition of SBFS can improve the hydration of cement and the pore structure of the matrix. For C40 concrete, the addition of SBFS increases both the $28 \mathrm{~d}$ and $90 \mathrm{~d}$ strength. But for C30 concrete, with the addition of SBFS, the increase in strength of $28 \mathrm{~d}$ is greater than that of $90 \mathrm{~d}$, which is also consistent with the phenomenon of mortar. This is due to the lower w/s of C40 compared to that of C30. Therefore, the addition of SBFS increases the strength development of the concrete at the lower w/s ratio.
Figure 3 also shows that for the same grade concrete, when the amount of cement is reduced, the $28 \mathrm{~d}$ strength decreases significantly, while the $90 \mathrm{~d}$ strength has little difference. This indicates that reducing the cement content can damage the $28 \mathrm{~d}$ strength, but improve strength development. The results of compressive strength show that reducing the amount of cement poses a negative effect on strength at the early age, while increasing the content of SBFS can improve the $28 \mathrm{~d}$ strength.

3.3. Performance of Self-Compacting Concrete. Two strength grades (C50 and C60) of self-compacting concrete were designed in this section to study the feasibility of preparing self-compacting concrete with composite admixture. Table 6 shows the mix proportion of self-compacting concrete. Selfcompacting concrete is often used in the pouring of mass concrete. Pure cement concrete (group C) was set as the control group.

Figure 4 shows the adiabatic temperature rise curve of C50 self-compacting concrete. The adiabatic temperature rises of concrete with pure cement, $\mathrm{Z} 1$, and $\mathrm{Z} 2$ at 7 days are $50.9^{\circ} \mathrm{C}, 45.95^{\circ} \mathrm{C}$, and $46.67^{\circ} \mathrm{C}$, respectively. The adiabatic temperature rises of concrete mixed with composite admixture are lower than that of pure cement concrete. This shows that the composite admixture of ultrafine slag and steel slag powder can significantly reduce the adiabatic temperature rise of concrete.

When the content of SBFS is increased, the adiabatic temperature rise grows higher. This indicates that SBFS can slightly increase the adiabatic temperature rise, which is the result of the smaller particle size of SBFS. The addition of SBFS can release the water in the pores, increasing the water around the cement and thus promoting the early hydration 
TABle 5: Mix proportion of concrete containing composite mineral admixture for compressive strength test $\left(\mathrm{kg} / \mathrm{m}^{3}\right)$.

\begin{tabular}{|c|c|c|c|c|c|c|c|c|}
\hline Grade & Group & $\mathrm{w} / \mathrm{s}$ & Cement & SS & SBFS & Sand & Aggregate & Water \\
\hline \multirow{2}{*}{ C30 } & $\begin{array}{l}\text { S-1 } \\
\text { S-2 }\end{array}$ & 0.47 & 200 & $\begin{array}{c}120 \\
112.5\end{array}$ & $\begin{array}{c}30 \\
37.5\end{array}$ & 780 & 1035 & 165 \\
\hline & $\begin{array}{l}\text { S-3 } \\
\text { S-4 }\end{array}$ & 0.45 & 175 & $\begin{array}{c}145 \\
131.2\end{array}$ & $\begin{array}{c}35 \\
43.8 \\
\end{array}$ & 790 & 1025 & 161 \\
\hline \multirow{2}{*}{$\mathrm{C} 40$} & $\begin{array}{l}\text { SS-1 } \\
\text { SS-2 }\end{array}$ & 0.395 & 250 & $\begin{array}{c}120 \\
112.5\end{array}$ & $\begin{array}{c}30 \\
37.5\end{array}$ & 730 & 1055 & 158 \\
\hline & $\begin{array}{l}\text { SS-3 } \\
\text { SS-4 }\end{array}$ & 0.385 & 200 & $\begin{array}{l}160 \\
150\end{array}$ & $\begin{array}{l}40 \\
50\end{array}$ & 720 & 1070 & 154 \\
\hline
\end{tabular}
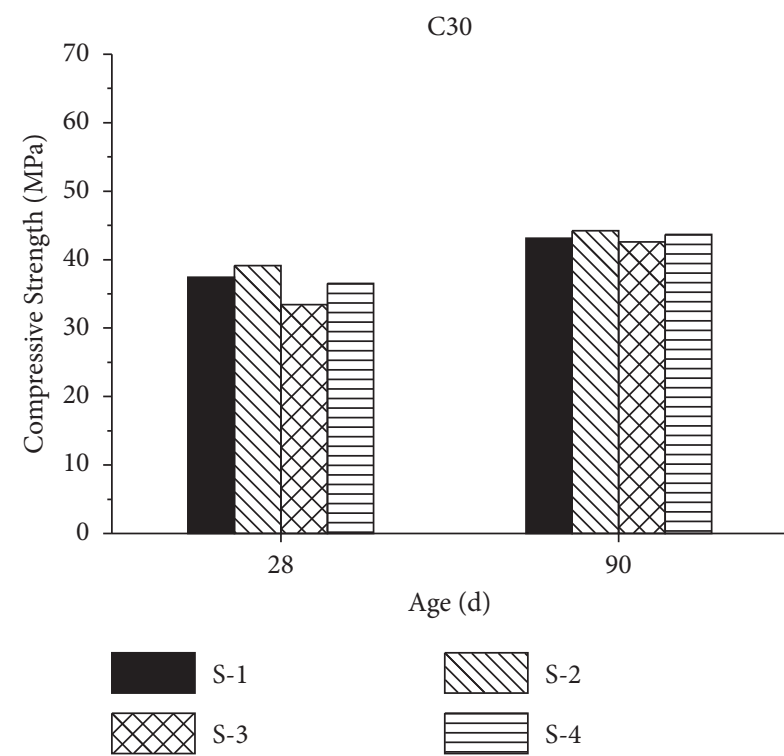

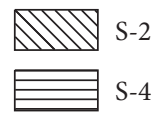

(a)
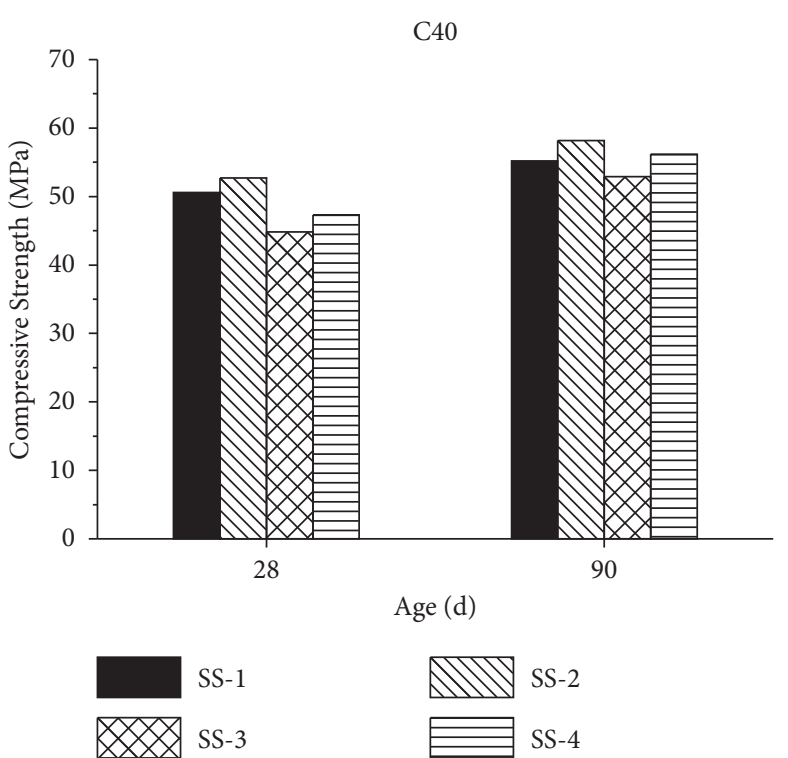

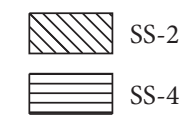

(b)

FIGURE 3: Compressive strength of concrete with composite admixture mortar: (a) C30 and (b) C40.

TABLE 6: Mix proportion of self-compacting concrete containing composite mineral admixture $\left(\mathrm{kg} / \mathrm{m}^{3}\right)$.

\begin{tabular}{|c|c|c|c|c|c|c|c|c|}
\hline Grade & Group & $\mathrm{w} / \mathrm{s}$ & Cement & SS & SBFS & Sand & Aggregate & Water \\
\hline C50 & $\begin{array}{l}\mathrm{Z} 1 \\
\mathrm{Z} 2\end{array}$ & 0.31 & 340 & $\begin{array}{l}128 \\
120\end{array}$ & $\begin{array}{l}32 \\
40\end{array}$ & 810 & 890 & 157 \\
\hline C60 & $\begin{array}{l}\mathrm{ZZ1} \\
\mathrm{ZZ2}\end{array}$ & 0.278 & 380 & $\begin{array}{l}144 \\
135\end{array}$ & $\begin{array}{l}36 \\
45\end{array}$ & 780 & 880 & 156 \\
\hline
\end{tabular}

degree of the cement. The larger specific surface area and the activity of SBFS can promote the nucleation of the C-S-H [32]. In addition, the pozzolanic reaction of SBFS can also release heat. Figure 4 also shows that the adiabatic temperature rises of group $\mathrm{Z} 2$ and $\mathrm{ZZ2}$ are higher than group $\mathrm{C}$ at $1 \mathrm{~d}$. While the adiabatic temperature rises of $\mathrm{Z} 1$ and $\mathrm{ZZ1}$ at $1 \mathrm{~d}$ is lower than pure cement concrete at $1 \mathrm{~d}$, the concrete mixed with higher SBFS increases the heat release before $1 \mathrm{~d}$. This proves that the addition of SBFS can improve the early hydration of cement.

Figure 5 shows the autogenous shrinkage of the selfcompacting concrete. The autogenous shrinkage of concrete mixed with composite admixture is less than that of pure concrete because less cement content was used. For C50 concrete, when the proportion of SBFS is increased from $20 \%$ to $25 \%$, the autogenous shrinkage is increased by $7.8 \%$. While for C60 concrete, with the same addition of SBFS, the autogenous shrinkage is only increased by $2.1 \%$. This indicates that the influence of the proportion of SBFS on the autogenous shrinkage decreases with the increase of concrete grade, which can be attributed to the fact that SBFS has better performance in promoting the hydration of cement at a low $\mathrm{w} / \mathrm{s}$. 


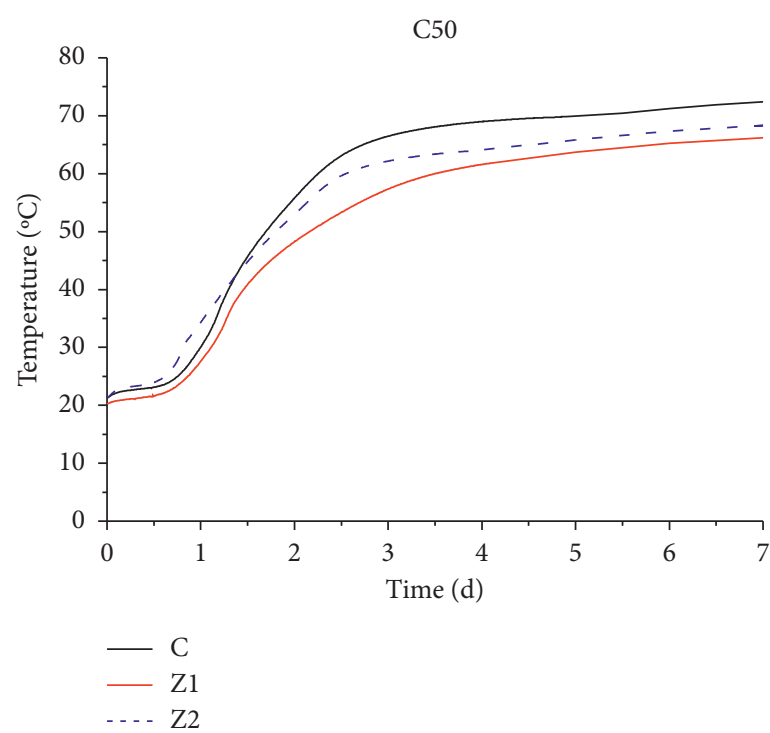

(a)

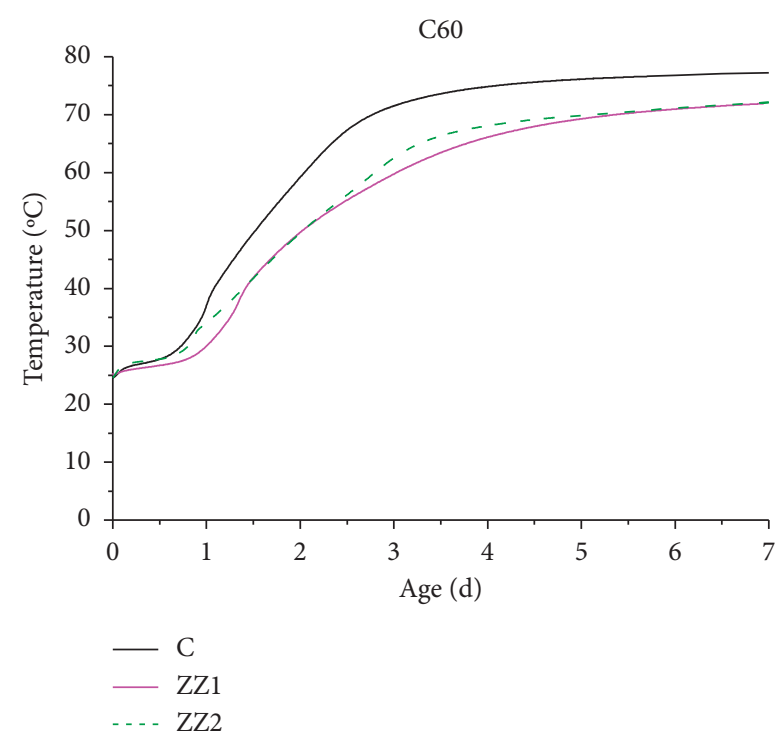

(b)

FIgUre 4: Adiabatic temperature rises of the self-compacting concrete: (a) C50 and (b) C60.

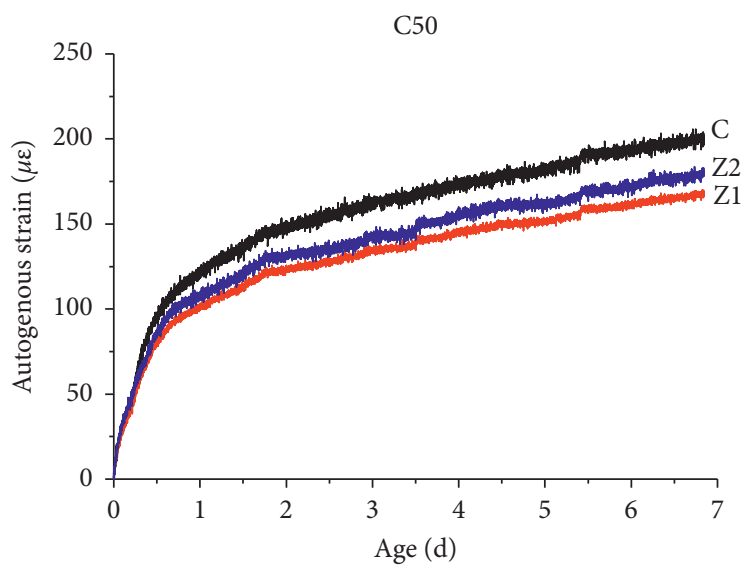

(a)

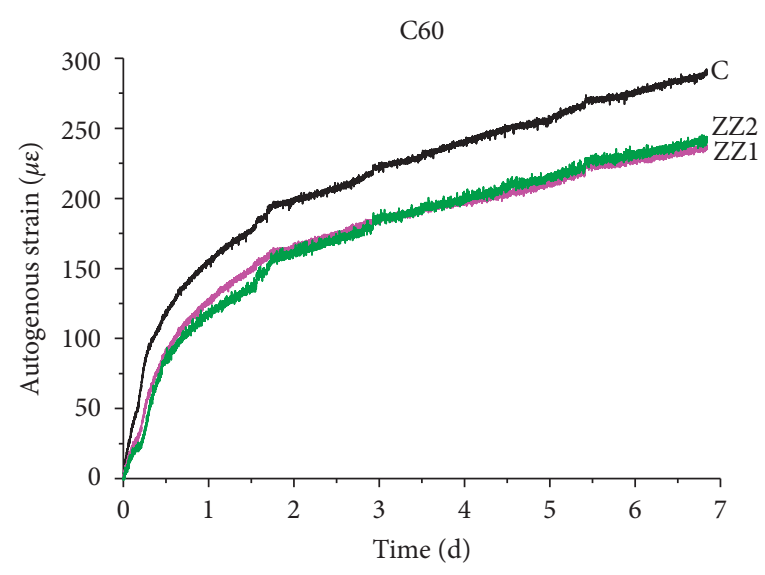

(b)

Figure 5: Autogenous shrinkage of the self-compacting concrete: (a) C50 and (b) C60.

\section{Conclusions}

In this study, a composite mineral admixture was used to replace cement. The fluidity and strength of the mortar, the strength of ordinary concrete, and the adiabatic temperature rise as well as the autogenous shrinkage of the self-compacting concrete were studied in this paper. The main conclusions are as follows:

(1) The addition of composite mineral admixture decreases the early strength of the mortar. Increasing the SBFS content of the composite admixture can reduce degradation of the early strength. This may contribute to the pozzolanic reaction of SBFS, enhancing interface transition zone.
(2) Composite admixture significantly reduces the adiabatic temperature rise of self-compacting concrete up to 7 days. For C50 concrete, the ladiabatic temperature rise increases with the addition of SBFS content. While for C60 concrete, the SBFS content has little effect on adiabatic temperature rise.

(3) Composite admixture significantly influences the autogenous shrinkage behavior of self-compacting concrete. The addition of composite admixture reduces autogenous shrinkage by $10 \%-15 \%$ for C50 concrete and $15 \%-20 \%$ for C60 concrete, respectively. The reduction effect of SBFS content on the autogenous shrinkage is prominent for C50 concrete compared to $\mathrm{C} 60$ concrete. This may be attributed to 
the reason that SBFS promotes the early hydration of cement at low w/s in C60 concrete and thus increases the autogenous shrinkage.

\section{Data Availability}

The experimental data used to support the findings of this study are included within the article.

\section{Conflicts of Interest}

The authors declare that there are no conflicts of interest regarding the publication of this study.

\section{Acknowledgments}

The authors would like to acknowledge the National Natural Science Foundation of China (no. 51822807).

\section{References}

[1] H. Ostovari, L. Müller, J. Skocek, and A. Bardow, "From ussa cement industry based on $\mathrm{CO} 2$ mineralization," Environmental Science \& Technology, vol. 55, no. 8, pp. 5212-5223, 2021.

[2] Y. Cancio Díaz, S. Sánchez Berriel, U. Heierli et al., "Limestone calcined clay cement as a low-carbon solution to meet expanding cement demand in emerging economies," Development Engineering, vol. 2, pp. 82-91, 2017.

[3] N. Mahasenan, S. Smith, and K. Humphreys, "The cement industry and global climate ChangeCurrent and potential future cement industry $\mathrm{CO} 2$ emissions," in Proceedings of the Greenhouse Gas Control Technologies-6th International Conference, pp. 995-1000, Kyoto, Japan, October 2003.

[4] B. Ma, X. Li, X. Wang, R. Dong, and H. Zhu, "Study on environmental load and the control approach in cement industry," Cement Engineering, vol. 2, pp. 79-82, 2005.

[5] D. Xu, Y. Cui, H. Li, K. Yang, W. Xu, and Y. Chen, "On the future of Chinese cement industry," Cement and Concrete Research, vol. 78, pp. 2-13, 2015.

[6] X. Chai, H. Kao, T. Guo, and Q. Zhang, "Study on thermal energy recovery methods of cement industry basing on the energy balance methods," Journal of Bulletin China Ceramic, vol. 32, no. 4, pp. 692-698, 2013.

[7] M. C. G. Juenger, F. Winnefeld, J. L. Provis, and J. H. Ideker, "Advances in alternative cementitious binders," Cement and Concrete Research, vol. 41, no. 12, pp. 1232-1243, 2011.

[8] J. Sun and P. Zhang, "Effects of different composite mineral admixtures on the early hydration and long-term properties of cement-based materials: a comparative study," Construction and Building Materials, vol. 294, Article ID 123547, 2021.

[9] Q. Wang, P. Yan, and G. Mi, "Effect of blended steel slagGBFS mineral admixture on hydration and strength of cement," Construction and Building Materials, vol. 35, pp. 8-14, 2012.

[10] X. Han, J. Feng, Y. Shao, and R. Hong, "Influence of a steel slag powder-ground fly ash composite supplementary cementitious material on the chloride and sulphate resistance of mass concrete," Powder Technology, vol. 370, pp. 176-183, 2020.

[11] P. Chindaprasirt, S. Homwuttiwong, and V. Sirivivatnanon, "Influence of fly ash fineness on strength, drying shrinkage and sulfate resistance of blended cement mortar," Cement and Concrete Research, vol. 34, no. 7, pp. 1087-1092, 2004.
[12] P. Chindaprasirt, C. Jaturapitakkul, and T. Sinsiri, "Effect of fly ash fineness on compressive strength and pore size of blended cement paste," Cement and Concrete Composites, vol. 27, no. 4, pp. 425-428, 2005.

[13] C. Shi, "Steel slag-its production, processing, characteristics, and cementitious properties," Journal of Materials in Civil Engineering, vol. 16, no. 3, pp. 230-236, 2004.

[14] İ. Yüksel, "A review of steel slag usage in construction industry for sustainable development," Environment, Development and Sustainability, vol. 19, no. 2, pp. 369-384, 2017.

[15] T.-S. Zhang, F.-T. Liu, S.-Q. Liu, Z.-H. Zhou, and X. Cheng, "Factors influencing the properties of a steel slag composite cement," Advances in Cement Research, vol. 20, no. 4, pp. 145-150, 2008.

[16] S. Kourounis, S. Tsivilis, P. E. Tsakiridis, G. D. Papadimitriou, and Z. Tsibouki, "Properties and hydration of blended cements with steelmaking slag," Cement and Concrete Research, vol. 37, no. 6, pp. 815-822, 2007.

[17] T. Zhang, Q. Yu, J. Wei, J. Li, and P. Zhang, "Preparation of high performance blended cements and reclamation of iron concentrate from basic oxygen furnace steel slag," Resources, Conservation and Recycling, vol. 56, no. 1, pp. 48-55, 2011.

[18] K. Wang, C. Qian, and R. Wang, "The properties and mechanism of microbial mineralized steel slag bricks," Construction and Building Materials, vol. 113, pp. 815-823, 2016.

[19] R. J. Galán-Arboledas, J. Álvarez de Diego, M. Dondi, and S. Bueno, "Energy, environmental and technical assessment for the incorporation of EAF stainless steel slag in ceramic building materials," Journal of Cleaner Production, vol. 142, pp. 1778-1788, 2017.

[20] L. D. Poulikakos, C. Papadaskalopoulou, B. Hofko et al., "Harvesting the unexplored potential of European waste materials for road construction," Resources, Conservation and Recycling, vol. 116, pp. 32-44, 2017.

[21] J. J. Feng, S. S. Wang, and X. Q. Wang, "Usage of steel slag in concrete as coarse aggregates," Advanced Materials Research, vol. 887-888, pp. 801-804, 2014.

[22] S. Liu and L. Li, "Influence of fineness on the cementitious properties of steel slag," Journal of Thermal Analysis and Calorimetry, vol. 117, no. 2, pp. 629-634, 2014.

[23] S. Zhuang and Q. Wang, "Inhibition mechanisms of steel slag on the early-age hydration of cement," Cement and Concrete Research, vol. 140, Article ID 106283, 2021.

[24] Y.-C. Peng and C.-L. Hwang, "Carbon steel slag as cementitious material for self-consolidating concrete," Journal of Zhejiang University - Science, vol. 11, no. 7, pp. 488-494, 2010.

[25] Q. Wang, D. Wang, and S. Zhuang, "The soundness of steel slag with different free $\mathrm{CaO}$ and $\mathrm{MgO}$ contents," Construction and Building Materials, vol. 151, pp. 138-146, 2017.

[26] M. Wu, Y. Zhang, Y. Ji et al., "Reducing environmental impacts and carbon emissions: study of effects of superfine cement particles on blended cement containing high volume mineral admixtures," Journal of Cleaner Production, vol. 196, pp. 358-369, 2018.

[27] P. Z. Wang, R. Trettin, and V. Rudert, "Effect of fineness and particle size distribution of granulated blast-furnace slag on the hydraulic reactivity in cement systems," Advances in Cement Research, vol. 17, no. 4, pp. 161-167, 2005.

[28] J. Zhu, Q. Zhong, G. Chen, and D. Li, "Effect of particlesize of blast furnace slag on properties of P," Procedia Engineering, vol. 27, pp. 231-236, 2012.

[29] T. Luo, Q. Wang, and S. Zhuang, "Effects of ultra-fine ground granulated blast-furnace slag on initial setting time, fluidity 
and rheological properties of cement pastes," Powder Technology, vol. 345, pp. 54-63, 2019.

[30] B. Lothenbach, G. Le Saout, E. Gallucci, and K. Scrivener, "Influence of limestone on the hydration of Portland cements," Cement and Concrete Research, vol. 38, no. 6, pp. 848-860, 2008.

[31] T. Zhang, Q. Yu, J. Wei, P. Zhang, and P. Chen, “A gap-graded particle size distribution for blended cements: analytical approach and experimental validation," Powder Technology, vol. 214, no. 2, pp. 259-268, 2011.

[32] A. K. H. Kwan and Y. Li, "Effects of fly ash microsphere on rheology, adhesiveness and strength of mortar," Construction and Building Materials, vol. 42, pp. 137-145, 2013.

[33] E. Berodier and K. Scrivener, "Understanding the filler effect on the nucleation and growth of C-S-H," Journal of the American Ceramic Society, vol. 97, no. 12, pp. 3764-3773, 2014.

[34] X. Ouyang, D. A. Koleva, G. Ye, and K. van Breugel, "Insights into the mechanisms of nucleation and growth of C-S-H on fillers," Materials and Structures, vol. 50, p. 513, 2017. 